\section{Riscos percebidos e vitimização de policiais civis e militares na (in)segurança pública}

\author{
Perceived risks and victimization of military and \\ civil police in the public (in)security domain
}

\author{
${ }_{1}^{1}$ Escola Nacional de Saúde \\ Pública Sergio Arouca, \\ Fundação Oswaldo Cruz, \\ Rio de Janeiro, Brasil. \\ Correspondência \\ M. C. S. Minayo \\ Centro Latino-Americano \\ de Estudos de Violência e \\ Saúde Jorge Careli, \\ Escola Nacional de Saúde \\ Pública Sergio Arouca, \\ Fundação Oswaldo Cruz. \\ Av. Brasil 4036, sala 700, \\ Rio de Janeiro, $R J$ \\ 21040-361, Brasil. \\ cecilia@claves.fiocruz.br
}

\begin{abstract}
This study was based on a larger survey on the socioeconomic, quality-of-life, occupational, and health characteristics of military and civil police in the State of Rio de Janeiro, Brazil. The study triangulated quantitative methods (an anonymous questionnaire in a random sample of clusters involving 46 police units and 2,678 police force members) and qualitative ones (18 focus groups with 143 police force members, 24 individual semi-structured interviews, and field observations). The article specifically approaches the issues of victimization and perceived risks among on-duty and off-duty police. Data were processed and analyzed according to risk-related variables. We performed a content analysis, comparing strata within and between police forces, according to thematic lines. This empirical approach is supported by secondary data analyses. According to our analysis, the police are the greatest victims in the performance of their duties, especially military police and those from both forces involved in direct law enforcement activities. Different variables are associated with risk in the two forces, with an emphasis on work conditions and especially involvement in other activities during their official off-duty time.
\end{abstract}

Risk; Vitimization; Police
Maria Cecília de Souza Minayo 1

Edinilsa Ramos de Souza 1

Patrícia Constantino 1

\section{Introdução}

Neste texto analisamos e comparamos vitimização e riscos percebidos por policiais militares e civis do Estado do Rio de Janeiro, Brasil, no exercício de sua profissão, dentro e fora do ambiente de trabalho. Apresentamos parte de uma pesquisa maior que investigou a concepção e a administração individual e coletiva dos riscos profissionais, financiada pela Secretaria Nacional de Segurança Pública do Ministério da Justiça 1. Os dados trazidos por nós sobre mortalidade, morbidade, percepção de risco e vitimização são inéditos, e trabalhos desse tipo são ainda escassos na lista de temas tratados por pesquisadores de saúde do trabalhador. Tradicionalmente os estudos enfatizam condições de saúde e trabalho dos operários industriais, tendência de toda a produção acadêmica do século 20 , fortemente influenciada pelas análises marxistas do mundo social. Como evidencia a ampla revisão bibliográfica sobre serviços no Brasil, coordenada por Melo et al. ${ }^{2}$, aqui e internacionalmente, a literatura sobre esse setor é muito escassa: serviços continua a ser a parte menos entendida da economia. Esse hiato conceitual, no entanto, destoa do que ocorre na realidade histórica, vale dizer, nas últimas décadas, esse setor tem representado quase dois terços do emprego urbano metropolitano no Brasil e responde por mais da metade do Produto Interno Bruto (PIB) 2. 
Risco é o conceito central do estudo, já que representa uma condição intrínseca à profissão policial. Os estudiosos que avaliam risco apontam que as situações englobadas por essa noção não podem ser consideradas apenas como processos objetivos e redutíveis a análises quantitativas, uma vez que fatores culturais afetam o julgamento dos indivíduos sobre ocorrências arriscadas.

Os policiais constituem uma categoria de servidores públicos para quem o risco não é mero acidente, mas desempenha papel estruturante das condições laborais, ambientais e relacionais. Esses profissionais têm consciência de que perigo e audácia são inerentes aos atributos de suas atividades. Seus corpos estão permanentemente expostos e seus espíritos não descansam.

O sentido do termo risco adequado para este estudo leva em conta sua definição epidemiológica e social. A primeira lhe dá parâmetros quanto à magnitude dos perigos, os tempos e os locais de maior ocorrência de fatalidades; a segunda responde pela capacidade e até pela escolha profissional do afrontamento e da ousadia. A percepção de risco que daí se depreende vem do caráter intrínseco da atividade policial; mas também, do fato de que todos têm porte de armas, tornandose alvos potenciais das agressões uns dos outros. Essa última circunstância é referida por eles na expressão "vivemos uma paz armada".

Alguns autores 3,4,5,6,7,8 analisam as similitudes dos vários tipos de polícia no mundo e especificam seu papel nos países periféricos. Mostram que, nos últimos, os policiais tendem a exceder o seu poder, a agir com truculência, a privilegiar as classes dominantes, acrescentando à sua missão constitucional uma terceira dimensão de ordem axial e atitudinal que os tornam autores de várias formas de violência ilegítima, sobretudo contra os pobres e o povo em geral.

Pretendemos mostrar que a combinação de vários ingredientes das respectivas culturas corporativas com as especificidades da "sociedade de risco" 9 tornou a visão de segurança pessoal no mundo atual muito problemática, especialmente para os policiais.

Perguntamo-nos sobre a vivência da vitimização e da percepção de risco, ao mesmo tempo subjetivo e objetivo, no exercício da profissão, dentro e fora do ambiente de trabalho. O foco também no âmbito externo da atividade corporativa se justifica pelo envolvimento que a profissão faz sobre a vida como um todo, de tal forma que as situações de risco vividas e percebidas impregnam o ambiente de trabalho, a pessoa e a instituição.

Problematizamos o conceito de segurança em dois sentidos: pública e pessoal. Segurança
Pública, segundo Silva 10, constitui a garantia que o Estado oferece aos cidadãos contra todo o perigo que possa afetar a ordem pública, em prejuízo da vida, da liberdade ou dos direitos de propriedade dos cidadãos: é a essência da missão dos policiais e deriva do campo jurídico. Segurança pessoal, segundo o mesmo autor, deriva do mundo do trabalho. No primeiro caso, representa a sistematização de normas destinadas a prevenir acidentes, eliminando condições inseguras e prevenindo desastres ocupacionais. Cuidando da segurança coletiva, os policiais são, também, servidores públicos protegidos pela Constituição Federal que lhes assegura o direito à integridade física e mental no exercício do trabalho.

\section{Material e método}

Trabalhamos com a estratégia de triangulação de métodos 11, lançando mão de técnicas quantitativas e qualitativas na abordagem empírica balizada por análises de dados secundários.

$\mathrm{Na}$ abordagem quantitativa, adotamos uma amostra aleatória simples de conglomerados. Entendemos como conglomerado a unidade física (uma delegacia, academia de polícia, batalhão etc.), com o seu respectivo grupo de profissionais. Na amostra, observamos diferenciações características do processo de trabalho das duas corporações. Em ambas foram estudadas unidades administrativas e unidades operacionais (delegacias, batalhões). As amostras foram calculadas com base em listagens da Secretaria de Segurança Pública e da Polícia Militar, contendo todas as unidades policiais da capital do Estado do Rio de Janeiro e o efetivo de cada uma delas, especificado segundo os cargos. Um dos critérios para o sorteio das unidades foi a natureza do processo de trabalho (administrativo, que constitui um conjunto de atividades-meio que dão suporte para as atividades-fim, isto é, a produção da investigação policial e repressão à criminalidade; operacional, responsável pela produção de registros de crimes e acidentes de trânsito, pela investigação de autoria de delitos, no caso da Polícia Civil; e pelo patrulhamento e enfrentamento da criminalidade, no caso da Polícia Militar. Tais ações são atividades-fim da função policial. Na Polícia Civil, foram selecionadas 38 unidades e 2.746 policiais, tendo sido pesquisadas 39 unidades e 1.458 policiais. $\mathrm{Na}$ Polícia Militar, sorteamos 15 unidades e 1.700 policiais, mas pesquisamos 18 unidades e 1.120 policiais. Tais discrepâncias se devem à necessidade de substituir unidades por dois motivos principais: algumas recusas dos gestores em participar da pesquisa e excessiva rotatividade dos 
policiais em seus locais de trabalho, implicando distorções entre o contingente real e as listagens fornecidas pelas administrações das duas forças. Aumentamos o número de unidade na tentativa de conseguir maior quantidade de respostas aos instrumentos de investigação.

Com o questionário, investigamos: (1) características sócio-econômicas; (2) qualidade de vida; (3) condições de trabalho e (4) condições de saúde. Esse instrumento, autopreenchido anonimamente, foi entregue em envelopes lacrados, acompanhados do termo de consentimento livre e esclarecido, conforme prevê a Resolução $n^{o}$. 196/96 do Conselho Nacional de Saúde. Nele, incorporamos escalas previamente estruturadas e validadas: Escala de apoio social e a SRQ-20 (Self Report Questionnaire) e de Qualidade de Vida ${ }^{12}$. A pesquisa de campo requereu muitas idas às unidades para cobrir os vários turnos das equipes e localizar os policiais, tanto visando à entrega quanto o seu recolhimento. Na prática, foram distribuídos muito mais questionários do que os recolhidos, pois o retorno dependia de um ato voluntário dos pesquisados.

Realizamos a expansão da amostra, procedimento estatístico que permite que dados obtidos de certo número de policiais passem a representar o coletivo deles lotados na capital (6.373 policiais civis e 21.075 policiais militares). As estimativas correspondentes a esse universo foram realizadas de forma indireta, mediante uso de fatores de expansão calculados como quocientes entre os universos $\mathrm{N}_{\mathrm{h}}$ de unidades e os correspondentes tamanhos de amostra $\mathrm{N}_{\mathrm{h}}$ pesquisada ${ }^{13}$. Aqui, $\mathrm{o}$ h representa a unidade policial (delegacia ou batalhão). Após a expansão, mesmo com uma considerável não-resposta aos questionários e uma possível redução na precisão das estimativas, verificamos que a amostra expandida ficou semelhante ao real contingente dos policiais. A crítica dos dados foi feita por: (1) procura de erros de codificação ou de digitação dos questionários; (2) e rastreamento de incoerências.

Os bancos de dados foram convertidos para o programa SPSS versão 10.0 (SPSS Inc., Chicago, Estados Unidos), com o qual realizamos a descrição de freqüências simples e cruzamento de todas as questões segundo variáveis Risco Percebido e Risco Vivido. No texto, essas diferenças apenas são mencionadas quando estatisticamente significativas $(\mathrm{p}<0,05)$.

Por meio de regressão logística foi feita uma modelagem em relação à vitimização dos policiais, sendo essa a variável de interesse no estudo. O indicador de vitimização, construído com base teórica por intermédio das seis questões dicotômicas referentes à auto-avaliação do risco reportada pelos policiais, envolveu atividades consideradas mais perigosas ao bem-estar físico do grupo operacional. Os tipos de violência mensurados pelo indicador nas situações de enfrentamento foram: ferimento por projétil de arma de fogo, ferimento por arma branca, agressão física, violência sexual, tentativa de suicídio e tentativa de homicídio. Na construção da variável de risco, optamos por trabalhar com a soma dos escores de respostas, sendo o zero referente ao que sofreu o menor grau de violência. Foi feita uma abordagem univariada, seguida por abordagem em blocos de variáveis e por uma terceira modelagem que uniu as duas anteriores.

$\mathrm{Na}$ abordagem qualitativa construímos instrumentos exercitando a triangulação metodológica: múltiplos informantes, observadores e técnicas de aproximação e compreensão da realidade. Elaboramos todos os instrumentos coletivamente e buscamos que fossem criticados por especialistas ad hoc nas áreas de saúde do trabalhador e de segurança pública.

Utilizamos três técnicas: grupo focal, entrevista semi-estruturada individual e observação de campo. Tanto as entrevistas como os grupos focais envolveram policiais dos setores operacional e administrativo e de distintos cargos. $\mathrm{Na}$ Polícia Civil, as entrevistas envolveram 11 macrogestores e gestores; na Polícia Militar, 8. Nos grupos focais participaram 51 profissionais $(40$ homens e 11 mulheres) da Polícia Civil e 92 policiais da Polícia Militar (84 homens e 8 mulheres). O número de pessoas ouvidas no qualitativo obedeceu a critérios de saturação da amostra, como preconizado na literatura. O roteiro das entrevistas enfatizou questões de administração e gestão. Os grupos focais ressaltaram o debate sobre situação e condições de trabalho, relações entre pares e hierarquias e percepções de risco.

A análise qualitativa de cunho temático cumpriu as seguintes etapas: (a) transcrição e digitação das gravações de entrevistas individuais e grupais; (b) atribuição de códigos aos entrevistados e às pessoas por eles mencionadas, para assegurar o sigilo das informações; (c) leitura compreensiva dos textos transcritos, identificando especificidades e visão global dos depoimentos; (d) elaboração de estruturas de análise, agrupando trechos de depoimentos significativos sobre processo de trabalho, risco, saúde; (e) identificação das idéias centrais presentes nesses eixos; (f) identificação dos sentidos atribuídos às idéias; (g) elaboração de sínteses interpretativas.

Realizamos um exercício comparativo entre os estratos dentro da mesma corporação e das duas corporações entre si. Desse processo foram obtidas novas sínteses interpretativas em torno de cada eixo temático. Observamos especificidades e intersecções entre as duas forças policiais. 


\section{Resultados}

\section{Riscos percebidos}

Embora haja muitas diferenciações no ethos e na dinâmica operacional das duas corporações, algumas similitudes as reúnem: a freqüência do risco e a percepção de viver em risco. Ainda que sentimentos de ousadia e destemor estejam mais aguçados no grupo operacional, todos dizem que ser policial jáéem si um risco. Neste sentido, poucas são as diferenças entre as duas corporações, entre a natureza da unidade (operacional ou administrativa) e entre os cargos.

A percepção de que o risco profissional abrange a todos em todos os momentos e recônditos da vida vem do fato de que, apesar de hoje alguém estar exercendo atividade-meio, sua tarefa amanhã poderá ser operacional por ordenação hierárquica ou por necessidade das demandas de segurança. Isso aproxima suas experiências. Por outro lado, o status policial está associado à atividade-fim, remetendo todos à compreensão do trabalhador coletivo.

No estudo quantitativo, levantamos questões sobre percepção de risco dos policiais. Os dados são apresentados na Tabela 1 .

Ressaltamos que a percepção de risco é quase totalizante para ambas as categorias. No entanto, ela é absoluta para os policiais militares, grupo em que nenhum membro se sente isento de risco profissional.

Entre policiais militares, os riscos reais e a percepção de risco são mais elevados mesmo para os que exercem quase que exclusivamente atividades de gestão e de comando. Isso ocorre primeiramente porque, em momentos especiais, todos são chamados para o front. Em segundo lugar, ao se verem obrigados a tomar decisões rápidas e solitárias, muitas vezes os oficiais acabam pondo em risco seus subordinados. Um dos gestores falou, emocionado, da quantidade de vidas que "ele já perdeu" em confrontos. Ressaltamos, contudo, que na vida real há uma diferença abissal de vitimização entre os que planejam (oficiais) e os que executam as operações (cabos e soldados, sargentos e subtenentes). Os dados confirmam o quanto tal diferença atinge negativamente os que estão no ciclo dos praças.

Se o risco na jornada de trabalho está mais presente no discurso dos operacionais, o perigo externo é sentido e vivenciado por todos. O trajeto para casa, as folgas e o lazer são momentos inseguros na concepção de todos. Ao considerarmos a soma dos riscos percebidos, do total de policiais militares $94,1 \%$ se dizem em risco fora do trabalho, contra $86,3 \%$ dos civis, sendo essa diferença significativa estatisticamente.

Para lidar com o sentimento de insegurança, a condição policial acaba por exigir um estilo de vida diferenciado. O exercício da atividade profissional invade a vida social e pessoal. A simbiose da natureza do trabalho com o modo e o estilo de vida pode ser constatada no slogan de um dos batalhões da Polícia Militar: "O espelho reflete você e você reflete o Batalhão da Polícia Militar". Assim, os servidores se sentem permanentemente "vigiados, tanto no Batalhão quanto fora dele". Sua vida como um todo tem como parâmetro a condição policial.

Tabela 1

Distribuição dos policiais civis e militares segundo percepção de risco em sua atividade policial e fora dela.

\begin{tabular}{|c|c|c|}
\hline Risco percebido na atividade policial & $\begin{array}{c}\text { Polícia Militar } \\
\%\end{array}$ & $\begin{array}{c}\text { Polícia Civil } \\
\%\end{array}$ \\
\hline Constante & 81,1 & 69,2 \\
\hline Eventual & 18,9 & 26,0 \\
\hline Não há risco & - & 4,8 \\
\hline $\begin{array}{l}\text { Total } \\
(p<0,000)\end{array}$ & 100,0 & 100,0 \\
\hline \multicolumn{3}{|l|}{ Risco percebido fora da atividade policial } \\
\hline No transporte coletivo (trajeto de ida e volta do trabalho) * & 86,8 & 91,3 \\
\hline Nas folgas * & 53,6 & 44,6 \\
\hline No exercício de outras atividades profissionais * & 63,5 & 56,0 \\
\hline
\end{tabular}

* Diferença estatisticamente significativa, $p<0,000$ 
A imersão total na identidade profissional é estimulada e vivida também pelos policiais civis. Os membros de ambas as categorias falam da permanente necessidade de se retirarem dela para respirar, para interagir com outros e para fugir aos riscos, particularmente nos momentos de folga. Ocultá-la é uma medida de proteção principalmente porque, ao contrário da situação dos policiais em outras sociedades como nos Estados Unidos, no Canadá, na Inglaterra, por exemplo, no Brasil - e especificamente no Rio de Janeiro - não se cultiva uma imagem positiva desses servidores públicos. A identidade profissional contribui assim para o sentimento de insegurança como comentado nos grupos focais a respeito do estresse no trabalho, mitigado pela união das equipes nas atividades cotidianas: "um precisa proteger o outro", “é o medo de morrer que aproxi$m a$ ", pois a situação de perigo nivela " $a$ todos no mesmo barco".

Nos grupos focais, os policiais também falaram de seus conflitos frente aos perigos. Nas unidades operacionais da Polícia Militar, dos oficiais ao círculo das praças, todos revelaram sentimentos de medo. A experiência concreta de situações de risco não permite a simples negação do enfrentamento da morte: "vemos colegas serem executados!". Por isso, os operacionais de ambas as Corporações têm uma experiência muito particular da urgência de vida e de proximidade da morte, cuja dialética entre provisoriedade e perenidade se reatualiza cotidianamente. Todos se sentem "em guerra" e percebem que alguns postos de trabalho significam "sentença de mor$t e$ " antecipada. Nas conversas de grupo, os policiais operacionais reportaram-se imediatamente a episódios de confronto e violência, e, na Polícia Militar, os praças se apresentam como o grupo que vivencia intensamente o risco cotidiano. $\mathrm{Na}$ fala de um gestor operacional: "para o soldado o risco é a rotina”. Entre os civis, os inspetores são os mais vulneráveis.

Profissionais de alguns batalhões estão alocados em área de elevado acirramento entre grupos rivais de traficantes de drogas. Um desses batalhões, sozinho, atende a 94 favelas onde as chamadas "guerras do tráfico" são cotidianas. Existe a circunstância agravante de que os grupos de traficantes são formados por jovens também ousados, aventureiros e prontos para o combate de vida ou morte. O sentimento de risco e as expressões de medo dos policiais são magnificados pela precariedade das viaturas, dos armamentos e das estratégias de ação nos confrontos diários com criminosos que usam armamentos mais potentes que os deles, conhecem em detalhes os locais de mira e esconderijos e chantageiam moradores para lhes dar guarida e proteção.

\section{Vitimização}

A vitimização se materializa em traumas, lesões ou mortes ocorridos na defrontação com a criminalidade e na manutenção da ordem. Dados da Secretaria Nacional de Segurança Pública (http://www.mj.gov.br/senasp/mapa, acessado em 03/Mar/2005) ajudam a estimar numericamente esse objeto de trabalho: para o ano de 2003 houve registro de 6.707 .955 ocorrências criminais nos Estados e de 2.264.829 nas capitais. No Estado do Rio de Janeiro, foram registradas 433.988 ocorrências, sendo 228.243 delas na capital.

A violência social é um fenômeno complexo e difícil de ser definido. Ele discrepa entre a ocorrência real e as sensações que gera. No imaginário, os sentimentos de medo e de insegurança levam a confundir crimes reais e percepções subjetivas sobre riscos, em proporções inversas. Uma dessas discrepâncias diz respeito à crença sobre permanente aumento da delinqüência, o que quase sempre não é real. A sensação de insegurança no Rio de Janeiro ocorre por vários motivos. Um deles, relacionado à própria dinâmica da criminalidade na capital onde há concentração da população do estado (40,2\%) e de delitos (52,6\%), o que difere de outras capitais e do país. Por exemplo, em São Paulo, apenas $27,6 \%$ da população do estado e 33\% das ocorrências criminais se concentram na capital. No país como um todo, esses valores se assemelham mais aos de São Paulo: 22,7\% da população e 33,8\% dos crimes se localizam nas capitais 14 .

Apresentamos uma síntese dos fatores associados à vivência de risco. Na Tabela 2, verificamos que para todos os tipos, exceto assédio ou agressão sexual, os militares têm maiores proporções de vítimas.

\section{- Policiais Militares}

As informações sobre os policiais militares (Tabela 3) referem-se a licenças para tratamento de saúde e incapacidade física parcial que requereram afastamento das atividades. Correspondem a afastamentos temporários por agravos que os retiraram de ações operacionais ostensivas, organizando-os em tarefas internas. Por mais que os dois tipos de afastamento tratem de todos os agravos, a Tabela 3 mostra como se distribuem tais ocorrências por hierarquia dos servidores.

Frisamos que o número médio de oficiais com licenças para tratamento de saúde cresceu 95,5\% no período, enquanto o de praças mais que duplicou (108,3\%). O número médio de praças, vítimas de agravos que exigiram afastamento é mais de vinte vezes o de oficiais ( $96 \%$ das licenças para tratamento de saúde no período). Os praças, 
Distribuição proporcional dos policiais civis e militares segundo os riscos vividos durante o trabalho policial.

\begin{tabular}{|c|c|c|}
\hline Riscos vividos & $\begin{array}{l}\text { Polícia Civil } \\
\%\end{array}$ & $\begin{array}{l}\text { Polícia Militar } \\
\text { \% }\end{array}$ \\
\hline Agressão verbal * & 30,0 & 38,6 \\
\hline Queda * & 11,1 & 24,6 \\
\hline Tentativa de homicídio * & 10,3 & 18,8 \\
\hline Agressão física ** & 8,2 & 10,3 \\
\hline Perfuração por arma de fogo *** & 4,2 & 6,7 \\
\hline Lesões por atropelamento ou acidente com veículo motorizado * & 1,7 & 6,6 \\
\hline Acidentes com animais usados no trabalho policial * & 0,5 & 6,4 \\
\hline $\begin{array}{l}\text { Explosão com lesões (combustíveis, bujão de gás, explosivos, } \\
\text { fogos, bomba, granada etc.) * }\end{array}$ & 0,7 & 5,3 \\
\hline Contaminação por bactérias ou outros microorganismos * & 2,7 & 5,1 \\
\hline Queimaduras por fogo ou químicas * & 0,3 & 3,3 \\
\hline Perfuração por arma branca * & 1,2 & 3,3 \\
\hline Tentativa de suicídio * & 0,3 & 2,9 \\
\hline Assédio ou agressão sexual & 2,8 & 2,6 \\
\hline Envenenamento, intoxicação por gases ou fumaça * & 0,4 & 1,9 \\
\hline Acidente por desmoronamento * & 0,3 & 1,6 \\
\hline
\end{tabular}

${ }^{*} p<0,000$;

$\star * * 0,05$;

$\star * * \mathrm{p}<0,005$

Tabela 3

Distribuição das licenças para tratamento de saúde e das incapacidades físicas parciais (IFP) dos policiais militares do Estado do Rio de Janeiro, Brasil, 2000 a 2004.

\begin{tabular}{|c|c|c|c|c|c|}
\hline \multirow[b]{2}{*}{ Licenças para tratamento de saúde } & \multicolumn{5}{|c|}{ Afastamento temporário } \\
\hline & 2000 & 2001 & 2002 & 2003 & 2004 \\
\hline \multicolumn{6}{|l|}{ Número médio } \\
\hline Oficial & 22,3 & 27,9 & 30,3 & 41,1 & 43,6 \\
\hline Praça & 539,8 & 685,0 & 801,8 & 919,3 & 1124,2 \\
\hline \multicolumn{6}{|l|}{ Proporção média } \\
\hline Oficial & 4,0 & 3,9 & 3,6 & 4,3 & 3,7 \\
\hline Praça & 96,0 & 96,1 & 96,4 & 95,7 & 96,3 \\
\hline Razão de número médio - Praça/Oficial & 24,2 & 24,6 & 26,5 & 22,4 & 25,8 \\
\hline \multicolumn{6}{|l|}{ Incapacidade física parcial } \\
\hline \multicolumn{6}{|l|}{ Número médio } \\
\hline Oficial & 79,2 & 105,0 & 136,6 & 162,7 & 211,1 \\
\hline Praça & $1.081,1$ & $1.307,0$ & $1.796,8$ & $2.123,2$ & $3.540,3$ \\
\hline \multicolumn{6}{|l|}{ Proporção média } \\
\hline Oficial & 6,8 & 7,4 & 7,1 & 7,1 & 6,0 \\
\hline Praça & 93,2 & 92,6 & 92,9 & 92,9 & 94,0 \\
\hline Razão de número médio - Praça/Oficial & 13,6 & 12,4 & 13,2 & 13,0 & 16,8 \\
\hline
\end{tabular}

Fonte: Souza \& Minayo ${ }^{14}$. 
como já dissemos, estão na linha de frente nos confrontos.

É preciso ressaltar o crescimento geral e as diferenças entre as duas categorias no que concerne a incapacitações físicas parciais: o número médio de oficiais com lesões e traumas cresceu $166,5 \%$ no período e o de praças, $227,5 \%$. O número médio de praças, no início da série, era cerca de 13 vezes maior que o de oficiais, passando a ser 16,8 vezes em 2004 . As praças corresponderam a $93 \%$ dos incapacitados físicos retirados dos serviços ostensivos para realizar tarefas internas, no período. No ano de 1997, 50,2\% das licenças para tratamento de saúde e $42,8 \%$ das incapacidades físicas parciais foram provocadas por traumas; e 5,6\% das licenças para tratamento de saúde e 16,9\% das incapacidades físicas parciais deveram-se a problemas psiquiátricos 15 .

A Figura 1 apresenta as taxas de vitimização dos policiais militares, nelas incluídas mortes e casos de ferimentos por ação violenta em serviço, em folga e todos os dados em conjunto.

Dos 4.518 policiais mortos e feridos por todas as causas, de 2000 a $2004,56,1 \%$ foram vitimados durante as folgas, contra 43,9\%, em serviço. Nesse período, a ação violenta representou $57,2 \%$ das causas de suas mortes e ferimentos, proporção que cresceu nos últimos dois anos, passando de $53,2 \%$ em 2002, para $63,7 \%$ e $67,1 \%$ em 2003 e 2004, respectivamente.
Do total de 758 policiais mortos, 173 (22,8\%) estavam em serviço. Quando mortos em serviço por ação violenta, essa proporção é maior $(26,4 \%)$. Os dados evidenciam, desde o ano de 2002, crescimento da proporção de óbitos em serviço por ação violenta, passando de $75 \%$ para $88 \%$. O número de policiais que perdeu a vida em serviço foi 2,5 vezes maior em 2004 quando comparado ao ano de 2000.

Cresceu a vitimização dos policiais, mas também é verdade que de 2003 para 2004 houve crescimento de 2,6\% no número de ocorrências criminais no Rio de Janeiro: foram 536.163 em 2003 e 550.262 em 2004. Os delitos violentos não letais contra a pessoa aumentaram $4,6 \%$, passando de 5.054 para 5.286. Coincidindo com a vitimização de policiais, a maioria dos crimes notificados na cidade aconteceu na Zona Norte.

Dados de óbitos por ação violenta indicam que morreram 2,8 vezes mais policiais militares em folga, em 2004, do que os que se encontravam em serviço. Porém, a importância da ação violenta é maior na mortalidade desses últimos (ela representa $83,2 \%$ das causas de óbito dos policiais que morreram em serviço, comparados aos $68,5 \%$ dos que morreram em folga) 14 .

Dos 3.760 policiais militares feridos (em serviço e em folga), 48,1\% (ou 1.809 policiais) estavam em serviço. Desses, 1.054 (58,3\%) foram atingidos em ação violenta, fato que representa

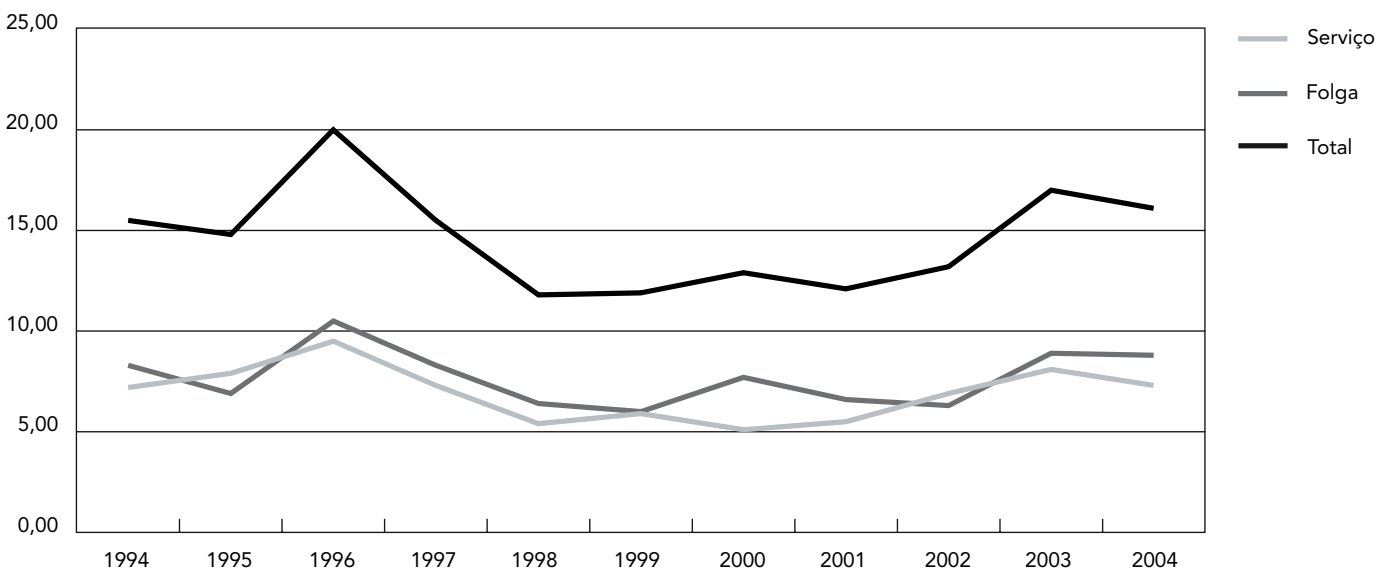

* Taxa por mil policiais.

Fonte: dados de Muniz \& Musumeci 15 para os anos de 1994 a 1997 e da Assessoria de Imprensa da Polícia Militar do Estado do Rio de Janeiro para os demais anos. 
uma proporção maior do que a de 50,5\% de feridos quando em folga pela mesma causa. Entretanto a ação violenta tem crescido proporcionalmente, vitimizando também os policiais em folga. Em 2003 e 2004, ela foi responsável por patamares acima dos $70 \%$ dos casos de ferimento desses profissionais. Em 2002, esse percentual foi de $39 \%$.

No período de 1994 a 1996, os praças representaram $55,3 \%$ dos policiais militares vitimados no Rio de Janeiro; os cabos, $31,1 \%$ do total; os sargentos, $8 \%$; e os oficiais, os $5,6 \%$ restantes. As categorias de vitimização em serviço foram: dinâmica criminal (54\%); trânsito (19\%); e dinâmica conflituosa $(21 \%)$.

Nas folgas, essas proporções foram de 35\%, $29 \%$ e $17 \%$, respectivamente. O principal meio usado pelos agressores para matar policiais em serviço (em média 51\%) e em folga (cerca de 55\%) foi arma de fogo. Acidentes de trânsito responderam por $20,4 \%$ das mortes em serviço e $28,1 \%$, em folga. O local das ocorrências corresponde às vias públicas $(72,7 \%)$; ao bairro $(6,3 \%)$; à vizinhança $(4,6 \%)$; à residência $(3,5 \%)$; ao espaço das próprias instituições policiais $(2,8 \%)$; aos bares e similares (2,1\%); e às instituições comerciais e financeiras $(3,3 \%)$.

Para o grupo dos policiais militares, ressaltamos os principais fatores de risco de sofrer violências: (a) tempo de serviço - policiais com menos tempo de serviço, com até dez anos sofreram 2,4 mais riscos no trabalho policial do que os mais antigos; (b) deficiências auditivas e nevralgias - policiais com deficiências auditivas ( 3 vezes mais) e nevralgias (4,1 vezes mais) relataram ter vivenciado mais riscos que os outros, indicando sofrimento físico associado a sofrimento mental pela vivência de situações de violência; (c) condições de trabalho - exercer outra atividade laboral além da polícia militar sem intervalo de descanso também se mostrou associado a vivenciar mais riscos decorrentes do trabalho policial. Os militares que têm outra atividade permanente, sofrem 5 vezes mais riscos de violência; e para os que exercem esporadicamente outra atividade sem descanso, o risco é duas vezes maior do que para os que cumprem apenas função no serviço público (Tabela 4).

\section{- Policiais civis}

No período de 1994 a 2004 foram aposentados por laudo médico 594 policiais civis, por todas as causas geradoras de invalidez temporária e permanente, incluindo-se doenças e lesões provocadas por acidentes e violência. Ao longo desses anos, a maior taxa de aposentadorias com aval médico ocorreu em 2004 (8,9 por mil policiais civis), enquanto a menor das taxas ocorreu em 2001, correspondendo a 3,4/mil.

Na Figura 2 apresentamos as taxas de mortalidade dos membros da corporação civil para os anos de 1994 e 1995 na cidade. No restante do período, elas se referem ao estado. Morreram, por todas as causas, 147 policiais civis no período de 1998 a 2004, dos quais a grande maioria (120) se encontrava em folga.

O ponto mais relevante das informações trazidas por esse gráfico é a elevação das taxas de morte de policiais civis nos dois últimos anos, principalmente quando em folga. Dos mortos em conseqüência do desempenho de suas atividades, $53,1 \%$ eram detetives; $10,9 \%$ carcereiros; $18 \%$ não foram especificados quanto à função; $5 \%$ eram escrivães, 3,8\% delegados e $8,4 \%$ exerciam outras funções. As circunstâncias da vitimização em serviço corresponderam à dinâmica criminal em 52\% dos casos, sendo 13,3\% por ação armada de suspeitos. Os acidentes de trânsito responderam por $22,7 \%$, e a dinâmica conflituosa, a 18,7\% dos traumas e lesões. As circunstâncias da vitimização dos que estavam em folga foram: dinâmica criminal (33,3\% dos casos, sendo 28,8\% a assaltos); acidentes de trânsito $(28,8 \%)$ e dinâmica conflituosa $(25,5 \%)$.

Os policiais civis de nível médio enfrentaram risco de violência duas vezes maior que os que possuem nível superior. Os que moderadamente aproveitam o tempo de lazer também vivenciam 2,2 mais risco de sofrer violência do que os que passam mais tempo em casa lendo, descansando ou dormindo (lazer domiciliar elevado). Essas informações reforçam a urgência de se criarem mecanismos de proteção dos policiais fora do tempo que passam na corporação.

Três variáveis referentes às condições de trabalho se mostraram importantes para o risco vivido pelos policiais civis: (a) treinamento insuficiente: os que não exercem o trabalho para o qual foram treinados passaram 2,3 vezes mais por situações de violência que os pares exercendo ações para as quais estão habilitados; (b) dupla jornada: entre os que sempre ou muitas vezes exercem outras atividades, sem descanso, fora da corporação, o risco de vitimização é 5 vezes maior do que os que não trabalham no "bico"; para os que exercem atividades extras de vez em quando, esse risco cai pela metade, mas ainda é 2,5 vezes maior; (c) estresse intenso: os que sentem estresse intenso no trabalho sofrem mais riscos que os outros: 3,4 vezes maior para os freqüentemente estressados.

Arma de fogo foi o instrumento responsável por $48,8 \%$ dos casos de vitimização dos policiais civis, seguida por situações envolvendo veículos (25\%) e luta corporal (13,5\%). A via pública cons- 
Variáveis associadas ao risco vivido por policiais militares e civis.

\begin{tabular}{|c|c|c|c|c|}
\hline \multirow[b]{2}{*}{ Variáveis $(N=853)$} & \multirow[b]{2}{*}{ Razões brutas } & \multicolumn{2}{|c|}{ Polícia Militar } & \multirow[b]{2}{*}{$\mathrm{IC} 95 \%$} \\
\hline & & IC95\% & Razões ajustadas & \\
\hline \multicolumn{5}{|l|}{ Perfil } \\
\hline \multicolumn{5}{|l|}{ Tempo de serviço (anos) } \\
\hline Até 10 & 2,22 & $1,17-4,25$ & 2,44 & $1,18-5,01$ \\
\hline $11-20$ & 1,54 & $0,72-3,31$ & 1,73 & $0,78-3,86$ \\
\hline 21 ou mais & 1,00 & - & 1,00 & - \\
\hline \multicolumn{5}{|l|}{ Saúde } \\
\hline \multicolumn{5}{|l|}{ Deficiência auditiva } \\
\hline Sim & 3,29 & $1,85-5,87$ & 2,98 & $1,61-5,52$ \\
\hline Não & 1,00 & - & 1,00 & - \\
\hline \multicolumn{5}{|l|}{ Nevralgias/Neurites } \\
\hline $\operatorname{Sim}$ & 5,13 & $2,56-10,27$ & 4,11 & $1,97-8,60$ \\
\hline Não & 1,00 & - & 1,00 & - \\
\hline \multicolumn{5}{|l|}{ Condições de trabalho } \\
\hline \multicolumn{5}{|l|}{ Exerce outra atividade sem descanso } \\
\hline Sempre/Muitas vezes & 5,24 & $2,84-9,66$ & 4,98 & $2,61-9,51$ \\
\hline Ás vezes/Poucas vezes & 2,51 & $1,34-4,71$ & 2,30 & $1,20-4,42$ \\
\hline \multirow[t]{2}{*}{ Nunca } & 1,00 & - & 1,00 & - \\
\hline & \multicolumn{4}{|c|}{ Polícia Civil } \\
\hline Variáveis $(N=475)$ & Razões brutas & IC95\% & Razões ajustadas & IC95\% \\
\hline \multicolumn{5}{|l|}{ Perfil } \\
\hline \multicolumn{5}{|l|}{ Escolaridade } \\
\hline Até $2^{\circ}$ grau incompleto & 1,75 & $0,59-5,18$ & 2,80 & $0,98-8,03$ \\
\hline $2^{\circ}$ grau completo/Superior incompleto & 2,62 & $1,64-4,18$ & 2,04 & $1,21-3,44$ \\
\hline Superior completo/Pós- graduação & 1,00 & - & 1,00 & - \\
\hline \multicolumn{5}{|l|}{ Lazer/Comunidade } \\
\hline \multicolumn{5}{|l|}{ Lazer domiciliar } \\
\hline Pouco lazer & 1,26 & $0,47-3,33$ & 1,33 & $0,45-3,91$ \\
\hline Moderado & 2,30 & $1,41-3,75$ & 2,23 & $1,31-3,80$ \\
\hline Elevado & 1,00 & - & 1,00 & - \\
\hline \multicolumn{5}{|l|}{ Condições de trabalho } \\
\hline \multicolumn{5}{|l|}{ Exerce o trabalho para o qual foi treinado } \\
\hline Não & 2,65 & $1,59-4,40$ & 2,29 & $1,29-4,04$ \\
\hline Sim & 1,00 & - & 1,00 & - \\
\hline \multicolumn{5}{|l|}{ Exerce outra atividade sem descanso } \\
\hline Sempre/Muitas vezes & 6,19 & $2,98-12,9$ & 4,96 & $2,24-11,0$ \\
\hline Ás vezes/Poucas vezes & 2,54 & $1,14-5,66$ & 2,45 & $1,05-5,73$ \\
\hline Nunca & 1,00 & - & 1,00 & - \\
\hline \multicolumn{5}{|l|}{ Trabalho causa estresse intenso } \\
\hline Freqüentemente & 4,23 & $2,16-8,28$ & 3,45 & $1,60-7,43$ \\
\hline Às vezes & 2,16 & $1,09-4,29$ & 2,09 & $0,96-4,53$ \\
\hline Raramente/Nunca & 1,00 & - & 1,00 & - \\
\hline
\end{tabular}




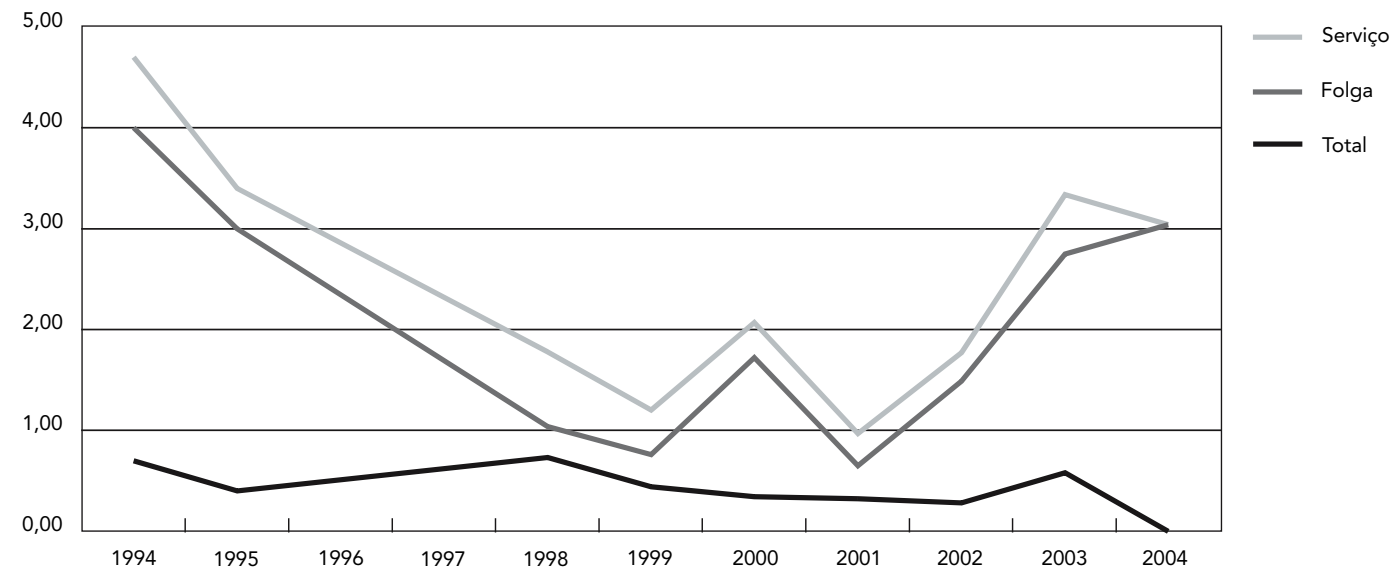

* Taxa por mil policiais.

Fonte: dfados de Muniz \& Musumeci 15 para os anos de 1994 a 1997 e da Assessoria de Imprensa da Polícia Militar do Estado do Rio de Janeiro para os demais anos.

tituiu o local de $63,2 \%$ das ocorrências. Contudo, parcela considerável de casos aconteceu em residências $(6,8 \%)$, nas próprias instituições policiais $(6,4 \%)$, no bairro $(5,6 \%)$ e em bares e similares $(5,3 \%)$.

\section{- Comparação entre as duas corporações}

Houve crescimento da vitimização nas duas corporações, sobretudo considerando-se lesões não fatais, em 2003 e 2004. As principais causas de morte, lesões e traumas se devem a agressões e a acidentes de trânsito, o que coincide hoje com informações sobre a vitimização das populações trabalhadoras no Brasil na conjuntura atual 16. Porém, a magnitude das ocorrências é muito mais insidiosa para policiais civis e militares no Rio de Janeiro.

Merece atenção a vitimização dos agentes de segurança em suas folgas, tanto em acidentes de trânsito como por agressões. No caso dos confrontos, algumas evidências podem ser ressaltadas. Uma delas se deve ao trabalho extra, também chamado "bico". Elevado percentual de policiais 14 tem um segundo emprego na área de segurança privada, continuando assim a usar o tempo livre com atividades de similar elevado risco. Outro motivo se deve à presença dos policiais, como cidadãos, em cenas de conflitos em bairros, em bares e em transportes quando, por via de sua função, acabam se envolvendo. Muitos, também, são vítimas de emboscadas de delinqüentes, levando uma grande maioria a esconder seus distintivos profissionais. Não deve ser descartado também o fato de que, no ambiente de trabalho das corporações, esses agentes desfrutem de maior proteção grupal e desenvolvam técnicas de cuidados muito mais estruturadas e precisas.

Fica patente que, comparativamente, a Polícia Militar é a que sofre mais agressões e morte, apresentando taxas de mortalidade e de morbidade elevadíssimas. Esse privilégio negativo pode ser constatado quando tomamos, por exemplo, dados para o ano de 2004. No Brasil, a taxa de mortalidade por homicídio na população geral foi de 27,0 por 100 mil habitantes e essa taxa na população masculina foi de 50,5. Na capital do Rio de Janeiro, as taxas são mais elevadas que a média do país tanto para a população geral (45,1/100 mil) como para a população masculina (89,3/100 mil).

As taxas de mortalidade por agressões e acidentes de trânsito para os agentes da segurança pública (das duas categorias) são ainda mais elevadas que as da população da cidade do Rio de Janeiro. Na Polícia Militar, em 2004, a taxa de mortalidade por agressões chegou a 292/100 mil. Na Polícia Civil, essa taxa, considerando-se todas as causas, no mesmo ano foi de 304/100 mil. Lo- 
go, comparativamente, a Polícia Militar apresenta uma mortalidade por violência 3,3 vezes maior do que a da população masculina da cidade do Rio de Janeiro e 6,5 vezes a da população geral da cidade. Comparadas com as do Brasil, as taxas são 5,8 vezes as da população masculina e 10,8 vezes as da população geral. Diferente do que ocorria em 2000, quando o risco de morte entre policiais militares era 1,72 mais elevado que o da Polícia Civil, em 2004 esses últimos passaram a ter uma taxa um pouco maior que a de seus colegas militares.

Quando observamos as informações sobre internações hospitalares motivadas por agressão, em 2004, elas corresponderam à taxa de 0,25 por mil habitantes na população geral e a 0,43 por mil na população masculina do país. As taxas de lesões e traumas por agressões não fatais foram de 13,19 para a Polícia Militar, nesse mesmo ano. Comparativamente, a taxa de morbidade hospitalar da Polícia Militar em 2004 foi 73 e 53 vezes maior que a da população geral da cidade do Rio de Janeiro e do Brasil, respectivamente. Nessa mesma ordem, foi também 40 e 31 vezes maior que a da população masculina do Rio de Janeiro e do Brasil.

\section{Discussões e conclusões}

\section{As conclusões deste estudo são de diversas ordens}

a) Sobre a falta de atenção à saúde do policial enquanto trabalhador: faz parte desse hiato do conhecimento do setor serviço, mas também por raízes históricas mais profundas. Bretas 7 (p. 21) observa, por exemplo, que o tema polícia tem sido sistematicamente inserido apenas como "apêndice da história das classes populares e do movimento operário, sobre o qual a polícia estendia sua implacável repressão". Há uma espécie de negação de positividade sociológica da categoria, lembrada tão somente na formalidade da aplicação da Lei. Além de outros motivos, a aversão ao tema remonta a um ranço que, desde a origem, opôs a população e intelectuais aos oficiais da segurança pública, fato acirrado nos períodos de ditadura militar. Por conseguinte, a consideração da segurança pública como assunto relevante para a construção da democracia e objeto da ciência social vem se consolidando apenas a partir dos anos 1990.

b) Sobre a urgência de tratar o tema do risco e da vitimização dos policiais: há necessidade de superarmos o vazio da ciência social em relação ao setor serviços e os problemas ideológicos que excluíram os agentes de segurança da pauta da cidadania. A literatura atual só agora vem apresentando aumento de investigações sobre essa categoria de servidores públicos 5,8,15,17,18,19,20, $21,22,23$.

c) Sob o ponto de vista da opinião pública: o serviço de segurança pública no Rio de Janeiro é malvisto e malquisto pela população por motivos diversos: os cidadãos das classes médias e abastadas reclamam da insegurança e da ineficiência policial, pois esperariam mais rigor e vigilância dos pobres "criminógenos", em função da ordem burguesa; a população pobre e moradora das periferias sente-se discriminada e maltratada pelos agentes da lei; e os delinqüentes os consideram inimigo número um, buscando evadir-se de seu olhar ou mesmo controlá-los e confrontá-los, escudados exatamente na sua "má fama”. Essa opinião pública negativa sobre policiais faz parte do ônus da atividade que desempenham no mundo inteiro e, nossos estudos mostram, acrescentando-se a outros como os de Amador 21, um elevado grau de sofrimento no trabalho pela falta de reconhecimento social.

d) Do ponto de vista comparativo: as informações evidenciam que os policiais militares e civis do Rio de Janeiro, além de viverem o risco como profissão são as maiores vítimas do desempenho de suas atividades. Policiais que sofreram elevado risco decorrente do trabalho são aqueles que mais vivenciaram violências do tipo: ferimento por projétil de arma de fogo ou por arma branca, agressão física, violência sexual, tentativa de suicídio e tentativa de homicídio. Diferentes variáveis se associam à vivência de risco nas duas corporações, destacando-se especialmente nas condições de trabalho, o exercício de outras atividades sem descanso, indicando sua importância para se pensar formas de prevenir os riscos vividos.

e) Sobre a organização do trabalho: observamos que alguns fatores predispõem e se associam à vitimização - excessiva rotatividade dos policiais dificulta o conhecimento dos problemas e a responsabilização pelos atos. A falta de instâncias coletivas de reflexão e avaliação do trabalho dificulta a superação das falhas e dos problemas que acabam sendo tratados apenas nos escalões hierárquicos superiores. O imediatismo, as condições materiais precárias de trabalho, as cargas horárias excessivas, o número insuficiente de profissionais e os salários inadequados ao risco e à importância da missão são elementos que contribuem para a baixa produtividade. $\mathrm{O}$ fato de mais da metade da corporação ter dupla vinculação de ocupação constitui sério problema para a saúde, para o desempenho profissional e para a produtividade das corporações. A pesquisa permite constatar que a falta de perspectiva 
global do processo de trabalho das duas corporações conduz a uma atitude imediatista, reativa e excessivamente focada nos aspectos operativos, provocando grande sofrimento mental aos policiais.

Concluindo, podemos inferir que os policiais, sobretudo os operacionais civis e militares, vivenciam um conflito entre o enfrentamento desejado pela instituição que ressalta os atributos e as marcas da masculinidade e os sentimentos de medo da morte, justificados pelas situações de risco reais e imaginárias a que estão submetidos. É urgente que nos comovamos com as absurdas taxas de morte dos policiais, ressaltando que não existe fatalidade nessa imensa perda de vidas que tanto afeta as famílias e a sociedade como um tudo.

\section{Resumo}

Este estudo se baseou em uma pesquisa maior que investigou características sócio-econômicas, qualidade de vida, condições de trabalho e de saúde de policiais militares e civis do Estado do Rio de Janeiro, Brasil. Para isso, foram triangulados métodos quantitativos (questionário anônimo, em amostra aleatória de conglomerados envolvendo 46 unidades policiais e 2.678 policiais) e qualitativos (18 grupos focais com 143 policiais, 24 entrevistas individuais semi-estruturadas e observações de campo). Neste artigo abordamos particularmente a vitimização e os riscos percebidos pelos policiais dentro e fora da Polícia. Os dados foram processados e analisados segundo variáveis relativas a risco. Realizamos análise de conteúdo, comparando estratos intra e entre corporações segundo eixos temáticos. Essa abordagem empírica é aqui balizada por análises de dados secundários. Evidenciamos que os policiais são as maiores vítimas do desempenho de suas atividades, sobretudo os militares e aqueles de ambas as corporações que exercem funções operacionais. Diferentes variáveis se associam à vivência de risco nas duas corporações, destacando-se as condições de trabalho, em especial, o exercício de outras atividades no período legal de descanso.

\section{Colaboradores}

M. C. S. Minayo, E. R. Souza e P. Constantino participaram igualmente da elaboração, análise e escrita do artigo.

\section{Agradecimentos}

Este trabalho constitui parte de uma pesquisa maior denominada Estudo Comparativo sobre Riscos Profissionais, Segurança e Saúde Ocupacional dos Policiais Civise Militares do Estado do Rio de Janeiro, realizada pelo Centro Latino-Americano de Estudos de Violência e Saúde Jorge Careli, Escola Nacional de Saúde Pública Sergio Arouca, Fundação Oswaldo Cruz da qual participaram os seguintes coordenadores e pesquisadores: M. C. S. Minayo e E. R. Souza (coordenadoras); P. Constantino (coordenadora do trabalho de campo); equipe de pesquisa: Simone Gonçalves de Assis, Raimunda Matilde N. Mangas, Miriam Schenker, Maria de Lourdes Tavares Cavalcante, Francisco Adolpho da Cunha Barros, Flávio Augusto Pinto Correa, Júlio César Vasconcelos Silva, Cleber Nascimento do Carmo; Thiago de Oliveira Pires, Bruna Soares Chaves, Vanessa dos Reis de Souza, Raquel Carvalhaes de Oliveira e Nilton C. dos Santos. 


\section{Referências}

1. Minayo MCS, Souza ER, organizadores. Estudo comparativo sobre riscos profissionais, segurança e saúde ocupacional dos policiais civis e militares do Estado do Rio de Janeiro. Rio de Janeiro: Centro Latino-Americano de Estudos de Violência e Saúde Jorge Careli/Secretaria Nacional de Segurança Pública; 2005.

2. Melo HP, Rocha F, Ferraz G, Sabatto A, Dweck R. O setor serviços no Brasil: uma visão global 1985/95. Rio de Janeiro: Instituto de Pesquisa Econômica Aplicada; 1998.

3. Lima MB, Lima H. A história da polícia do Rio de Janeiro. Rio de Janeiro: Editora A Noite; 1942.

4. Holloway TH. Polícia no Rio de Janeiro: repressão e resistência numa cidade do século XIX. Rio de Janeiro: Fundação Getulio Vargas; 1997.

5. Kahn T. Índices de criminalidade: construção e uso na área de segurança pública. Rev Ilanud 1997; 2:21-8.

6. Bretas ML. Observações sobre a falência dos modelos policiais. Tempo Social 1997; 9:79-94.

7. Bretas ML. Ordem na cidade: o exercício cotidiano da autoridade policial no Rio de Janeiro, 19071930. Rio de Janeiro: Editora Rocco; 1997.

8. Santos JVT. A arma e a flor: formação da organização policial, consenso e violência. Tempo Social 1997; 9:155-67.

9. Giddens A. Modernidade e identidade. Rio de Janeiro: Jorge Zahar Editor; 2002.

10. Silva P. Vocabulário jurídico. Rio de Janeiro: Editora Forense; 1998.

11. Minayo MCS. Conceito de avaliação por triangulação de métodos. In: Minayo MCS, Assis SG, Souza ER, organizadores. Avaliação por triangulação de métodos: abordagem de programas sociais. Rio de Janeiro: Editora Fiocruz; 2005. p. 19-51.
12. Minayo MCS, Souza ER, organizadores. Missão investigar: entre o ideal e a realidade de ser policial. Rio de Janeiro: Editora Garamond; 2003.

13 Cochran WG. Técnicas de amostragem. Lisboa: Editora Fundo de Cultura; 1965.

14. Souza ER, Minayo MCS. Policial, risco como profissão: morbi-mortalidade vinculada ao trabalho. Ciênc Saúde Coletiva 2005; 10:917-28.

15. Muniz J, Musumeci B. Mapeamento da vitimização de policiais no Rio de Janeiro. Rio de Janeiro: Centro de Estudos de Segurança e Cidadania; 1998.

16. Minayo-Gomez C, Lacaz FAC. Saúde do trabalhador: novas e velhas questões. Ciênc Saúde Coletiva 2005; 10: 797-808.

17. Cerqueira CMN. Discursos sediciosos: crime, direito, sociedade. Rio de Janeiro: Editora RelumeDumará; 1996.

18. Cerqueira CMN. O futuro de uma ilusão: o sonho de uma nova polícia. Rio de Janeiro: Instituto Carioca de Criminologia/Fundação Ford/Editora Freitas Bastos; 2001.

19. Cerqueira CMN. A polícia em uma sociedade democrática. Rio de Janeiro: Polícia Militar do Rio de Janeiro; 1994. (Série Cadernos de Polícia, 20).

20. Donicci, VL. Polícia, guardiã da sociedade ou parceira do crime: um estudo de criminologia. Rio de Janeiro: Editora Forense Universitária; 1990.

21. Amador FS. Violência policial: verso e reverso do sofrimento. Santa Cruz do Sul: EDUNISC; 2002.

22. Lima RK. A polícia da cidade do Rio de Janeiro: seus dilemas e paradoxos. Rio de Janeiro: Editora Forense; 1995.

23. Costa ATM. Entre a lei e a ordem: violência e reforma nas polícias do Rio de Janeiro e Nova York. Rio de Janeiro: Fundação Getúlio Vargas; 2004.

Recebido em 20/Set/2006

Versão final reapresentada em 18/Abr/2007

Aprovado em 02/Mai/2007 